\title{
De custody chain à cadeia de custódia: incompatibilidades do controle protocolar com o sistema cartorial da Justiça Criminal Brasileira
}

\author{
From custody chain to cadeia de custódia: protocols \\ incompatibilities with the notarial Brazilian Criminal Justice \\ System
}

Roberto Kant de Limal

Izabel Saenger Nuñez ${ }^{2}$

Mauricio Mendonça de Carvalho ${ }^{3}$

\begin{abstract}
RESUMO
Este artigo parte da análise um caso criminal, consistente na apreensão de fuzis no aeroporto do Galeão/RJ, utilizado como ferramenta empírica e analítica, de modo a explicitar os problemas e as dificuldades de implantação da cadeia de custódia no caso brasileiro. A partir de uma analise contrastiva, buscamos explicitar o modo como as provas são tratadas no sistema de justiça brasileiro e norte-americano, expondo que a simples importação da custody chain não afasta os problemas de um sistema cartorial/inquisitorial, como o que temos no Brasil.
\end{abstract}

\section{PALAVRAS-CHAVE:}

Cadeia de custódia; sistema judicial; provas; Brasil e EUA.

\begin{abstract}
This paper compares, through the analysis of a criminal case, related to a rifles seizure at Galeão Airport, in Rio de Janeiro, which is used as an empirical and analytical tool in order to show the limits and difficulties to implant custody chain in Brazilian Criminal System. Based on

\footnotetext{
${ }^{1}$ Pesquisador 1-A do CNPq; Cientista do Nosso Estado/FAPERJ; Professor dos Programas de Pós-Graduação em Antropologia e em Justiça e Segurança da UFF e de Direito da Universidade Veiga de Almeida; Coordenador do Instituto Nacional de Ciência e Tecnologia, Instituto de Estudos Comparados em Administração de Conflitos (INCT-InEAC - www.ineac.uff.br).

${ }^{2}$ Doutora em Antropologia pelo PPGA/UFF (2018). Doutoranda em Direito pela UERJ. Mestre em Ciências Jurídicas e Sociais pelo PPGSD/UFF (2012). Bacharel em Ciências Jurídicas e Sociais pela PUCRS (2007). Atualmente é pesquisadora de pós doutorado (PNPD/CAPES) vinculada ao Núcleo Fluminense de Estudos e Pesquisa (NUFEP/PPGA/UFF); Vice coordenadora do Núcleo de Estudos e Pesquisas sobre Sujeitos, Sociedade e Estado (NEPSSE/UFF); e pesquisadora do Instituto Nacional de Estudos Comparados em Administração Institucional de Conflitos (INCT-InEAC). Contato: izabelsn@gmail.com.

${ }^{3}$ Mestrando em Direito pela Universidade Veiga de Almeida (UVA-RJ). Pós-graduando em gestão de projetos e processos em segurança pública pela COOPEAD/UFRJ. Delegado de Polícia Civil do Estado do Rio de Janeiro (PCERJ). Professor de Direito Constitucional. Membro do Conselho Curador da Fundação de apoio ao ensino e pesquisa e desenvolvimento da Polícia Civil RJ - FAEPOL.
} 
contrast, we intent to show how evidences are treated in Brazil and in the United States, exposing that simply importing custody chain won't solve the problems related to Brazilian notary and inquisitorial system.

\section{KEY-WORDS:}

Custody chain; judicial system; evidences; Brasil and United States;

\section{INTRODUÇÃO: PROBLEMAS METODOLÓGICOS NA IMPORTAÇÃO DE INSTITUTOS JURÍDICOS}

No contexto do direito brasileiro, é comum, desde há muito, a importação de modelos oriundos de outras tradições jurídicas. Foi assim, por exemplo, o caso do Tribunal do Júri (KANT DE LIMA, p. 203-219, 2019), inserido no Brasil no período em que sediava o Reino de Portugal e, que, como devidamente apontado à época por Pimenta Bueno (1849), ao ser "transportado de solo, sua árvore seus frutos feriu". Como temos demonstrado (NUÑEZ, 2018, no prelo; KANT DE LIMA, 2019) o júri foi importado do modelo inglês de trial by jury e adaptado à sociedade brasileira, de modo que assumiu desde o início um formato que contrasta com aquele das sociedades da common law, onde se originou. O mais notável aspecto nele modificado foi que sua primeira versão imperial, surgida no Código de Processo Penal de 1831, que definia sua competência universal para julgar todos os crimes levados à justiça. Com o passar do tempo, restringiu-se paulatinamente esta competência até chegarmos à atual versão do Código de Processo Penal de 1941, tornando-se apenas uma fase do processo presente unicamente nos casos crimes intencionais contra a vida humana. Isso contrasta drasticamente com a sua versão na commom law, onde representa um direito universal dos cidadãos em todos os casos em que são acusados de crimes graves.

No entanto, esse fenômeno de importação de institutos de maneira acrítica é fato que chama nossa atenção, pois ainda contemporaneamente os doutrinadores do campo do direito seguem louvando e buscando validar a inserção de tais instrumentos como fonte de aperfeiçoamento de nosso sistema. Fenômeno que se dá especialmente em relação aqueles oriundos do modelo judicial dos EUA, como se representassem a solução para problemas de 
política judicial brasileira, à semelhança do que se dava no século retrasado (AMORIM; KANT DE LIMA; MENDES, 2005). Recentemente, podemos identificar esse fenômeno quando agentes deste campo pleiteiam a importação de elementos como o da "justiça criminal negocial" e, ainda, da "cadeia de custódia" ou dos "standards probatórios".

Aqueles que o fazem esquecem de levar em contar os contrastes entre as dinâmicas processuais, culturais e sociais dos contextos analisados, quer do modelo em que serão inseridas, quer no sentido de compreender de modo global e por contraste, as particularidades das práticas de onde e como foram aplicadas originalmente, em especial os diferentes sentidos de justiça, ou sensibilidades jurídicas, que orientam suas finalidades e avaliam seu desempenho (GEERTZ, 1983).

Por exemplo, nos Estados Unidos, o trial by jury é um direito constitucional do acusado, que opta por não negociar sua culpa ou admitir sua responsabilidade, seja na área criminal, seja na cível. Devido a essa recusa, deverá enfrentar a acusação em um julgamento que será feito diante de um juiz, muitas vezes eleito pela comunidade local, e de jurados, selecionados aleatoriamente na lista de eleitores registrados no local, que desempenharão seu papel como uma contraprestação do direito do cidadão de ter julgada sua pretensão. Há regras muito estritas do que pode e do que não pode ser mencionado nesse julgamento (exclusionary rules), de antemão discutidas pelas partes em audiências preliminares diante do juiz, que toma a decisão final quanto aos procedimentos a serem adotados durante todo o julgamento. Essa orientação a de que só vai a julgamento aquele que não aceita a acusação, caracteriza o trial by jury como um direito do acusado, tendo o julgamento a finalidade precípua, portanto, de inocentá-lo, a seu pedido, pois está exercendo um direito seu, do qual pode desistir a qualquer momento, até ser proferida a decisão do corpo de jurados, interrompendo o processo. Assim, o critério de eficiência do trial by jury é medido pelo número de absolvições que promove, cumprindo seu papel de instrumento dos injustamente acusados de provarem suas não culpabilidades. Sim, porque o trial by jury não prova a inocência de ninguém, apenas demonstra que a acusação não tinha evidências suficientes para condenar o acusado. Assim fazendo, o trial by jury é um instrumento legal que impõe explicitamente uma rigorosa separação entre o que se sabe e o que se pode provar, característica que deveria ser comum a todos os processos que garantem a liberdade dos cidadãos, fazendo valer a presunção de sua inocência, até prova em contrário (beyond a reasonable doubt). 
Da mesma forma, quando falamos, por exemplo, em plea bargain ou custody chain, nos referimos a dinâmicas processuais completamente distintas das que temos aqui no Brasil e que, no nosso caso, se assentam em regras nem sempre explícitas. Para continuar com o exemplo do Tribunal do Júri, considerado há muito por juristas brasileiros (FRANCO, 1956) uma cláusula pétrea da Constituição referente à garantia dos direitos dos cidadãos (à semelhança dos Estados Unidos), ele não se constitui em um julgamento completo, em que todas as evidências têm que ser construídas e apresentadas diante dos jurados, em tempo real. Consiste sim em uma fase final de uma longa instrução criminal, registrada em "autos" de um processo administrativo/judicial, que começa geralmente pelo indiciamento do acusado no inquérito policial e se desdobra na denúncia do promotor, que dá início ao processo penal e a sua fase instrutória, conduzida pelo juiz. Como mencionado, somente nos casos específicos de crimes intencionais contra a vida humana o acusado é pronunciado ${ }^{4}$, tornando-se réu (ou seja alterando sua classificação processual) e, enfim, sendo obrigatoriamente submetido ao Tribunal do Júri. Ou seja, o acusado sofre uma culpabilização progressiva durante esse percurso, registrada nos autos dos cartórios policiais e judiciais, cujos documentos são dotados de fé pública.

Como consequência disso, não é de estranhar que pesquisas constatem que o resultado esperado desse julgamento não é a absolvição (quando, estranhamente, o réu seria considerado “inocente”), mas a condenação. Ao invés de ser um direito subjetivo do acusado, do qual ele pode desistir, como na common law, aqui o julgamento do júri é uma fase de um processo a que o réu deve se submeter, obrigatoriamente, em função das acusações que contra ele pesam (KANT DE LIMA, 2019; NUÑEZ, no prelo; LOBO, no prelo). Por isso, há muito as pesquisas realizadas no âmbito do InEAC e fora dele ${ }^{5}$ (Cf. por exemplo, FERREIRA, 2004, 2013 e FIGUEIRA, 2005, 2008) demonstram que, embora nossa Constituição disponha que todos os acusados têm direito à presunção da inocência, na prática, todo o procedimento policial, registrado nos autos e posteriormente entranhado no processo penal, na grande maioria dos casos leva a sua condenação, especialmente se iniciado com um auto de prisão em flagrante

\footnotetext{
${ }^{4}$ Antes da reforma de 2008 o Código de Processo Penal determinava o lançamento do nome do acusado no rol de culpados após a decisão de pronúncia.

${ }^{5}$ O Instituto de Estudos Comparados em Administração de Conflitos - INCT-InEAC. Trata-se de um Instituto Nacional de Ciência e Tecnologia, sediado na UFF, que foi aprovado em fevereiro de 2009, pelo Ministério de Ciência e Tecnologia, através do Programa "Institutos de Ciência e Tecnologia" - Edital 15/08 MCTI; posteriormente, foi novamente aprovado na CHAMADA INCT - MCTI/CNPq/CAPES/FAPs nº 16/2014, sendo financiado pelo CNPq, CAPES e FAPERJ até 2022.
} 
elaborado pela autoridade da polícia judiciária (MISSE, 2010; KANT DE LIMA: MOUZINHO, 2016; LOBO, no prelo).

Assim, ainda que sob o argumento de aprimorar o sistema de justiça criminal brasileiro, não é possível negar ou omitir os imensos contrastes com os sentidos de justiça dos outros sistemas, quando se pretende compreendê-lo ou alterá-lo. Na verdade, justamente ao explicitálos é que se poderia propor soluções adequadas e capazes de dar conta dos problemas oriundos do contexto cultural, social e jurídico em que vivemos.

\section{ALGUMAS CARACTERÍSTICAS DO "SISTEMA DE JUSTIÇA CRIMINAL NO BRASIL" E DO CRIMINAL JUSTICE SYSTEM DOS EUA}

O "sistema de justiça criminal brasileiro", que sequer poderia ser chamado como tal", tem formas de produção da verdade fragmentadas, isto é, separadas por fases e guiadas por princípios distintos. A "verdade" policial é construída em um contexto inquisitorial, monológico, no chamado "inquérito policial", averbada de modo cartorial pela polícia. Depois, o processo segue para a sua fase judicial, onde será produzida outra verdade, essa orientada pelo princípio do contraditório, mas controlada pelos magistrados. Finalmente, quando é o caso, passa ao tribunal do Júri, onde os debates entre acusação e defesa destinam-se a desenvolver performances retóricas voltadas para a persuasão dos jurados, que em muito se assemelham aos desafios presentes no sistema da "prova legal” (KANT DE LIMA, 2009; FOUCAULT, 1999). No entanto, durante todo esse trajeto, os autos do processo circulam sempre certificados pelo sistema cartorário, dotado de fé pública e que, portanto afiança a autenticidade dos documentos ali registrados. Assim. quando se coloca em dúvida a procedência ou a a autenticidade de algum deles, não se está desafiando apenas a credibilidade das partes, mas a própria credibilidade da instituição cartorial e de seus serventuários, ou funcionários. ${ }^{7}$ Nesse sentido, as pesquisas de

\footnotetext{
${ }^{6}$ Não são poucas as pesquisas que demonstram a inexistência de um "sistema de justiça criminal" no Brasil (PAIXÃO, 1982; KANT DE LIMA, 2004; PAES, 2006). Isso porque a ideia de sistema presume uma continuidade e uma integração institucional, que não acontece no caso brasileiro, que se apresenta de modo partido e cujas agências (polícia, ministério público e judiciário), mobilizadas por princípios de construção da verdade jurídica distintos, não se comunicam de forma articulada e competem entre si no exercício das suas funções.

${ }^{7}$ Essa é uma das dificuldades da avaliação nas Audiências de custódia sobre o uso de violência nas prisões efetuadas pela polícia. Quando vêm à Audiência de Custódia, os presos já foram registrados nos autos com o Auto
} 
Kant de Lima (2019) e Michel Misse (2010) demonstraram como a fase policial é determinante para o andamento das demais etapas do processo.

Outra particularidade do caso brasileiro é que a prova deixa de ser o resultado de uma produção das partes, como no caso dos EUA (GARAPON E PAPADOPOULOS, 2008), e passa a ser uma escolha dos magistrados dentre as versões contraditórias produzidas pelas partes, por meio do princípio do "livre convencimento motivado" assegurado aos juízes por lei ${ }^{8}$ e que permite que eles continuem produzindo provas $^{9}$ mesmo quando acusação e defesa estão de acordo sobre elas (GRINOVER, 1999; MENDES, 2012). Significa dizer, portanto, que a prova aqui não obedece às mesmas regras que no sistema dos EUA, em que ela é produzida pelas partes, supervisionada pelo juiz e limitada pelas regras de exclusão (exclusionary rules), como acima mencionado (BISHARAT, 2014).

Para explorar o contraste existente entre os dois contextos, descreveremos um caso ocorrido no Brasil, mas que, por se tratar de um crime internacional, ao ser enviado para os Estados Unidos acabou por gerar uma série de conflitos. Tais conflitos explicitam a maneira contrastiva como agentes brasileiros e dos Estados Unidos lidam com a prova, em função das diferentes regras que determinam sua validade processual nos dois contextos.

Metodologicamente, o caso surge aqui como uma ferramenta empírica e analítica (GLUCKMAN, 1975), isto é, para a demonstração e compreensão não apenas dele, mas em diálogo com as demais práticas que observamos ao longo de nossas trajetórias como pesquisadores. Assim, embora seja apresentado isoladamente nesse artigo, permite demonstrar as rotinas e as exceções, identificadas nas práticas que acompanhamos durante o trabalho de campo intensivo, ao longo da realização de nossas pesquisas. Apresentaremos, assim, o caso que ficou conhecido pela apreensão de sessenta fuzis de guerra, dentro de uma carga de aquecedores de piscinas, no aeroporto internacional do Galeão, no Rio de Janeiro, no ano de $2017^{10}$.

\footnotetext{
de Prisão em Flagrante, onde a Autoridade policial, o Delegado de Polícia, atestou no cartório a regularidade da prisão (Abreu, 2019).

${ }^{8}$ Art. 155 do Código de Processo Penal.

${ }^{9}$ Art. 156, I e II, do Código de Processo Penal.

${ }^{10}$ Sobre o caso, reportagem do G1, disponível em <https://g1.globo.com/rio-de-janeiro/noticia/policia-civilapreende-60-fuzis-de-guerra-no-aeroporto-internacional-do-rio.ghtml>. Acesso em: 19, jan., 2021.
} 


\section{O CASO DA CARGA DE FUZIS APREENDIDOS NO AEROPORTO DO GALEÃO/RJ}

Na manhã do dia 1o de junho de 2017, a Polícia Civil do Estado do Rio de Janeiro deflagrou uma operação policial para a apreensão de 60 fuzis no terminal de cargas do aeroporto internacional do Rio de Janeiro - o Galeão. Em razão de uma investigação sigilosa, registrada em um inquérito policial, tomou conhecimento de que duas remessas, oriundas de Miami, Flórida, Estados Unidos da América, estavam no terminal de cargas do aeroporto, no bairro da Ilha do Governador, recheadas de armamentos que, à oportunidade da investigação, não se sabia precisamente que tipo de armas, ou mesmo se eram armas ou apenas munições, prestes a serem retiradas. Eram 08 aquecedores de água - water heaters, distribuídos em duas cargas, 04 em cada, que acondicionavam armas de fogo em seu interior, pois delas havia sido retirado todo o conteúdo elétrico e hidráulico.

Já no aeroporto, os objetos foram de fato identificados e foi determinado pelo Delegado de Polícia a sua imediata colocação em um aparelho de raio-x, onde se verificou a presença de armas no interior dos aquecedores. Detectadas as armas pelo raio-x, os aquecedores foram abertos e deles começaram a ser retirados os diversos fuzis, concretizando-se a maior apreensão de fuzis em aeroportos do mundo. Naquele momento os armamentos foram dispostos no chão do terminal e checados pelos policiais civis e federais, estes últimos, acionados em razão do local ser um aeroporto internacional. Toda a operação era observada por auditores da Receita Federal e funcionários do local.

Depois, os fuzis foram novamente colocados nos water heaters e levados de viatura policial para a Cidade da Polícia Civil ${ }^{11}$, onde funcionava a sede da delegacia responsável pela diligência. Lá, foi organizada uma grande coletiva de imprensa, oportunidade em que os Delegados da cúpula da instituição e até o Secretário de Segurança Pública ${ }^{12}$ estiveram

\footnotetext{
${ }^{11}$ A Cidade da Polícia é um complexo que pertence à Polícia Civil onde ficam sediadas diversas delegacias especializadas, além de outros órgãos da estrutura da PCERJ. Foi inaugurada no ano de 2013 e está localizada no bairro do Jacaré, zona norte da cidade do Rio de Janeiro. Há, no terreno que foi doado ao estado, nove blocos e uma área de treinamento dos policiais, que conta com uma "favela cenográfica", além de estande e casa de tiros. Para mais informações, vide: <https://exame.com/brasil/cidade-da-policia-civil-e-inaugurada-no-rio/>. Acesso em 08, jan., 2021.

${ }^{12}$ Hoje a Polícia Civil do Estado do Rio de Janeiro é secretaria própria, não havendo mais órgão político entre o chefe da instituição e o chefe do Poder Executivo.
} 
presentes para anunciar a festejada apreensão. As armas foram exibidas à imprensa e manuseadas por diversos policiais, muitos dos quais não eram lotados na delegacia que desencadeou a apreensão.

O fato foi amplamente noticiado na imprensa, e consequentemente observado pelos agentes da US Immigration and Customs Enforcement - ICE/US $S^{13}$ que de imediato enviaram um policial ao Rio de Janeiro para buscar informações acerca da diligência, haja vista que o material era originário dos Estados Unidos da América.

Com o agente dos EUA em solo fluminense deu-se início a uma grande troca de informações, objetivando a elucidação da autoria, ou seja, a busca pela descoberta do real emissário dos fuzis apreendidos. Por essa razão, os policiais brasileiros foram convidados pelo governo dos EUA a comparecer ao estado da Flórida/EUA a fim de que pudessem conversar com os agentes dos EUA designados para a investigação naquele país, bem como para que pudessem expor em detalhes como se deu a diligência policial ao Federal Prosecutor ${ }^{14}$. Foram convidados Policiais Civis, Policiais Federais e uma Procuradora da República ${ }^{15}$.

A comitiva brasileira esteve em Miami por 03 dias consecutivos (entre 17 e 19 de julho de 2017) no Miami Office da US Immigration and Customs Enforcement, onde foram realizadas reuniões com policiais da ICE/US, da Bureau of Alcohol, Tobacco, Firearms and Explosives $A T F^{16}$ e com o Federal Prosecutor, oportunidade em que foram expostas as peculiaridades da investigação brasileira (era um caso complexo, investigado num inquérito sigiloso, que já tramitava há cerca de 02 anos).

Meses depois o inverso aconteceu, os policiais americanos e o Federal Prosecutor estiveram no Rio de Janeiro, na Cidade da Polícia Civil, para conversar com os policiais civis, e buscar entender como havia se dado o processo de "cadeia de custódia" dos fuzis apreendidos. Isto é, como havia sido mantida a integridade da prova, no caso dos fuzis.

\footnotetext{
${ }^{13}$ A ICE/US é a agência dos EUA que exerce a função de polícia de imigração e alfândega. De acordo com o site institucional, tem por missão "proteger as fronteiras da nação e salvaguardar a integridade do sistema de imigração" <https://www.ice.gov>. Acesso em 08, jan., 2021.

${ }^{14}$ Mal comparando é o nosso Procurador da República, ou seja, quem detém atribuição para acusar alguém de um crime federal.

15 A despeito do fato estar sendo investigado pela polícia estadual, naquele momento, no âmbito processual já havia se dado o declínio de competência da justiça estadual à federal, por isso a atuação do MPF, como determinam as regras processuais brasileiras, pois quando o crime trata de questões internacionais, a competência é federal.

${ }^{16}$ A ATF é a agência policial dos EUA que apura o tráfico interno de álcool, tabaco, armas de fogo e explosivos.
} 
$\mathrm{Na}$ primeira reunião houve surpresa por parte dos policiais brasileiros, posto que o Federal Prosecutor buscava saber os nomes de todos os que haviam participado da diligência e, mais do que isso, queria conhecer o local onde as armas estavam acondicionadas, quem teve acesso a elas, quem as manuseou, além de diversos outros detalhes que, para a polícia brasileira, eram irrelevantes: por exemplo, onde os aquecedores estavam acautelados, onde estava a embalagem original do produto, dentre outras informações que, para a polícia brasileira, eram consideradas desimportantes "minúcias".

A reunião foi extensa e exigiu grande esforço de memória para que nenhum nome fosse esquecido, posto que, segundo o Federal Prosecutor, isso poderia comprometer a eficácia da acusação em solo americano. Naquele momento o autor do crime já havia sido identificado e estava preso nos EUA, após ser flagrado com outros 52 fuzis que estavam na iminência de serem remetidos ao Brasil. Os policiais americanos visitaram todas as instalações pelas quais as armas passaram, ainda que de maneira temporária. Delas tiraram fotografias e relacionaram todos os servidores que tinham acessado aqueles setores, mesmo que não tivessem manuseado as armas.

Como, àquela época, o pacote anticrime ainda não havia sido publicado, não existiam exigências legais a serem atendidas, no que se refere à manutenção do material apreendido. Por isso, após a apreensão, a embalagem original (caixa de papelão) foi descartada no aeroporto e o material apreendido seguiu para o auditório da Cidade da Polícia Civil, onde foi apresentado à imprensa e, posteriormente, cartorialmente formalizado, por meio da elaboração do auto de apreensão na delegacia ${ }^{17}$. Depois, foi remetido à Coordenadoria de Armas e Explosivos da Polícia Civil - CFAE, onde foi periciado e armazenado na sala-cofre até a decisão judicial que deferiu seu perdimento ${ }^{18}$.

Para a legislação processual brasileira e para o conjunto das práticas policiais (KANT DE LIMA, 2019), não importava quem havia tocado nas armas, por quais setores da Polícia Civil elas haviam passado, quem tinha autorização para acessar a sala-cofre onde estavam acauteladas, dentre outras questões indagadas pelo Federal Prosecutor quando em visita ao Brasil.

\footnotetext{
${ }^{17}$ Como mencionado anteriormente, o que dá validade aos atos do inquérito e do processo, no Brasil, é seu registro cartorial, que tendo fé pública, passa a valer até que seja demonstrado pelo acusado o contrário.

${ }^{18}$ A juíza do caso determinou o encaminhamento das armas ao Comando do Exército Brasileiro, na forma do art. 25 da Lei 10.826/03.
} 
Ocorre que a cadeia de custódia era instituto que há muito já existia nos Estados Unidos, em função da indispensável validação de sua integridade, se necessário, para que possa se tornar uma evidência em um futuro julgamento. Por essa razão, tais peculiaridades exerciam influência direta na maneira de atuação do Federal Prosecutor, haja vista o sistema de justiça criminal vigente naquele país.

Posteriormente, o autor do crime (felony) foi identificado, e no dia 30 de janeiro de 2018 foi acusado pelo estado americano perante a Corte do Distrito Sul da Flórida, - ato conhecido como indictment, onde constou na Penalty Sheet os crimes de (I) Conspiração contra os Estado Unidos - Conspiracy to Commit Offenses against the United States, (II) Entrega de armas de fogo a transportador sem notificação escrita - Delivery of Firearms to a Contract Carrier without Written Notification, (III) Contrabando de mercadoria para fora dos Estados Unidos Smuggling Goods Outside of the United States e (IV) Exportação ilegal de armas de fogo Exporting Firearms without a License, onde as penas somadas alcançariam 40 anos de prisão.

Menos de 30 dias após o oferecimento da acusação, a polícia dos EUA localizou um galpão com outros 52 fuzis, prestes a serem remetidos ao Brasil, o que possibilitou a prisão do acusado. Por isso, no dia 16 de maio de 2018 houve a celebração do acordo - plea agreement entre acusação e defesa, com o estabelecimento da verdade consensual, restando ajustada a declaração de culpa - guilty pela remessa ilegal de fuzis ao Rio de Janeiro, Brasil, no período de 06 de maio de 2013 a 26 de maio de 2017.

Segue pequeno trecho do plea agreement no que se refere especificamente ao reconhecimento da remessa ilegal das armas apreendidas pela Polícia Civil do Estado do Rio de Janeiro, pela qual o acusado concordou com as acusações e aceitou a pena de 12 anos que lhe foi imposta. A diferença da pena máxima das acusações totais inicialmente formuladas foi reduzida em função das lacunas encontradas na produção das evidências no lado brasileiro:

Among those shipments, on or about May 26, 2017, the Defendant willfully shipped firearms and firearm accessories concealed in water heaters from the United States to Rio de Janeiro, Brazil. 
Como se pode ver, desde a nossa descrição sobre a maneira que os procedimentos em relação às provas no Brasil e nos Estados Unidos e, sobretudo em razão da surpresa com que os policiais americanos encararam o tratamento dado por nós às provas, se verifica um contraste especialmente no que se refere aos protocolos por eles adotados.

\section{CUSTODY CHAIN E CADEIA DE CUSTÓDIA, DEVIDO PROCESSO LEGAL E DUE PROCESSO OF LAW}

No final do ano de 2019, foi editada a Lei n. 13.964, conhecida como "pacote anticrime", publicada em 24 de dezembro, e que entrou em vigor 30 dias após sua publicação. Tal lei trouxe importantes modificações no Código de Processo Penal, dentre elas a introdução da cadeia de custódia, prevista no capítulo II do CPP, que passou a ter o seguinte título: "DO EXAME DE CORPO DE DELITO, DA CADEIA DE CUSTÓDIA E DAS PERÍCIAS EM GERAL”.

Com isso, foram acrescentados ao Código de Processo Penal os artigos 158-A, 158-B, 158-C, 158-D, 158-E e 158-F, que listam de forma detalhada toda a "cadeia de custódia" a ser seguida pelos agentes públicos que reconhecerem um elemento como de potencial interesse para produção da prova. Segundo o artigo 158-A a cadeia de custódia é:

o conjunto de todos os procedimentos utilizados para manter e documentar a história cronológica do vestígio coletado em locais ou em vítimas de crimes, para rastrear sua posse e manuseio a partir de seu reconhecimento até o descarte.

O texto define como "vestígio", "todo objeto ou material bruto, visível ou latente, constatado ou recolhido, que se relaciona à infração penal”. Sobre esse material, a lei determina que seja feito um "rastreamento", listado em diversas etapas, como "reconhecimento, isolamento, fixação", dentre outras. Os vestígios devem ser preferencialmente recolhidos por "perito oficial" (art. 158-C) e "todos os institutos de criminalística deverão ter uma central de custódia destinada à guarda e controle dos vestígios, e sua gestão deve ser vinculada diretamente ao órgão central de perícia oficial de natureza criminal" (art. 158-E). Ainda, a 
central de custódia deverá ter "serviços de protocolo, com local para conferência, recepção, devolução de materiais e documentos, possibilitando a seleção, a classificação e a distribuição de materiais, devendo ser um espaço seguro e apresentar condições ambientais que não interfiram nas características do vestígio".

Aprofundando o resumido exemplo acima descrito, do contraste entre o trial by jury e o Tribunal do Júri, elaborado a partir dos EUA através de dados de pesquisa de campo lá realizada $^{19}$ e de experiências de pesquisas efetuadas ao longo dos últimos anos no Brasil, pretendemos produzir uma análise comparativa por contraste ${ }^{20}$, entre o "devido processo legal brasileiro" e o due process of law.

O devido processo legal ${ }^{21}$ foi inserido no Brasil, expressamente, pela Constituição da República Federativa do Brasil de 1988, mais precisamente no artigo 5º LIV, a despeito do reconhecimento que já emergia da doutrina, extraída do texto constitucional precedente. No Brasil, o devido processo surge como uma construção doutrinária, ou seja, voltada para orientar um vir a ser jurídico, tendo por objetivo garantir ao cidadão um processo regular, com suas lógicas decorrências, dentre elas o contraditório e a ampla defesa. Carlos Roberto Siqueira Castro o define como:

(...) natural identificação da cláusula do devido processo legal com as solenidades da jurisdição criminal deve-se não apenas à evolução dialética do processo penal, em

\footnotetext{
${ }^{19}$ Os dados sobre o sistema de justiça dos EUA foram construídos etnograficamente por Roberto Kant de Lima junto à bibliografia especializada, durante a realização de seu doutorado em Harvard, EUA e no decorrer de um período de pesquisa de campo e observação participante, como antropólogo e bacharel em Direito durante permanência em Birmingham, Estado do Alabama (1990) e, posteriormente, em dois períodos (1990 e 2011-2012), em San Francisco, Estado da Califórnia. Na primeira oportunidade recebeu bolsa de pós-doutorado da Comissão Fulbright e na segunda, financiamento de pós-doutorado sênior da CAPES. Em ambas as ocasiões contou com apoio acadêmico e logístico do Professor George Bisharat, ex-defensor público da cidade de San Francisco, CA, atual Professor of Law (Criminal Procedure) do Hastings College of the Law da UCSF e Dr. em Antropologia pela Harvard University. Nessas ocasiões consultou extensivamente bibliografia especializada e praticou observação participante com a polícia de Birmingham e com a defensoria e promotoria nas Superior Criminal Courts em San Francisco e condados adjacentes. Posteriormente o Professor Bisharat esteve várias vezes no Brasil, quando fez conferências em reuniões da Associação Brasileira de Antropologia e publicou textos em revistas de antropologia e sociologia sobre o sistema de justiça dos EUA. O Professor Bisharat é um dos consultores internacionais do INCT-InEAC desde 2009.

${ }^{20}$ Optamos pela escolha do método comparativo por diferença (DUMONT, 1966, 1976; GEERTZ 1989), em torno da qual se organiza o saber antropológico contemporâneo. Na trajetória da constituição da disciplina, de muitas maneiras foram respondidas as questões de o quê, como e por quê comparar. Essas respostas formaram corpos teóricos e hoje fazem parte do patrimônio da disciplina. O que lhes é comum, é que embora dirigida para o conhecimento de outras sociedades, do "outro", a antropologia é uma ciência europeia e ocidental, basicamente comprometida com os pontos de vista de sociedade onde se tornou necessária sua constituição (AMORIM; LIMA; MENDES, 2005).

${ }^{21}$ Para uma análise aprofundada do tema, cf. FERREIRA, 2013.
} 
cujas cercanias floresceu o instituto, mas também ao fato de que é justamente nesse setor que o conceito de idoneidade processualística mais vivamente se subsume em garantias do contraditório e da ampla defesa dos acusados, o que significa dizer, numa palavra, em garantia da liberdade. (CASTRO, 2010, p.. 273)

Nos Estados Unidos o due process of law remonta a 1787, quando da proclamação do Bill of Rights que introduziu, dentre outras, a $5^{\mathrm{a}}$ emenda à Constituição norte-americana. Além do contido nela, o princípio do due process of law foi novamente consagrado pela promulgação da $14^{\mathrm{a}}$ emenda. Nesse sentido, trata-se de um valor ordenador (DUMONT, 1985) do funcionamento do sistema de justiça dos EUA, tal como demonstrado por Ferreira (2013). No entanto, embora tais princípios sejam traduzidos no contexto brasileiro como se sinônimos fossem, produzem resultados distintos no funcionamento e aplicação prática do processo penal nesses dois países ${ }^{22}$. A palavra devido - due no contexto dos Estados Unidos, significa uma dívida do Estado para com seus cidadãos ${ }^{23}$, diferentemente daqui em que, por ser o processo penal obrigatório, havendo indícios de materialidade e autoria, não há como falar em processo criminal como direito subjetivo ou garantia de proteção dos cidadãos contra o eventual arbítrio do Estado. Trata-se, apenas de procedimento a que o estado obrigatoriamente deve submeter os cidadãos antes de condená-los. Melhor seria, portanto, empregar a tradução que se usava anteriormente à Constituição de 1988, a de devido processo regular ${ }^{24}$.

Nesse sentido, lá o processo é um direito constitucional do acusado, que escolhe se submeter ao processo penal, o Trial by Jury. Trata-se, pois, de uma opção, da qual pode abrir mão em razão da plea bargain (BISHARAT, 2015). A plea bargain é a negociação entre acusação e defesa a fim de tentar estabelecer um consenso. Trata-se, por isso, de uma negociação cooperativa que leva a aceitação de uma determinada culpa - guilty - acertada previamente pelas partes e que pode não guardar consonância com os tipos penais das acusações anteriormente imputadas. Nesse momento, que pode se dar a qualquer tempo, desde o cometimento do delito até o minuto anterior a revelação do veredito do Trial by Jury, o district attorney ${ }^{25}$ oferece ao defensor uma proposta de acordo para encerramento do caso. E, para

\footnotetext{
${ }^{22}$ Aqui novamente, para melhor compreensão cf. AMORIM; LIMA; TEIXEIRA MENDES, 2005.

${ }^{23}$ KANT DE LIMA; MOUZINHO; NUÑEZ, 2019.

${ }^{24}$ Significa que, embora o discurso jurídico constitucional descreva o processo penal como um "direito", no Brasil o réu é a ele submetido sem qualquer chance de escolha. Basta que o MP, "titular da ação penal", tenha indícios de materialidade e autoria para que possa elaborar a denúncia. Também as partes (acusação e defesa) não podem formalmente abrir mão do processo e precisam dar continuidade a ele, mesmo que previamente saibam a pena que querem ver aplicada aos réus.

${ }^{25} \mathrm{Na}$ esfera federal esse papel é do Federal Prosecutor, também chamado de United States attorney;
} 
tanto, utiliza como base um caso padrão - standard case - e aponta porque na circustância em análise a pena deve ser aumentada. A defesa consequentemente busca mostrar os pontos nos quais a pena deve ser menor que a do caso padrão. Dependendo das possibilidades maiores ou menores de a acusação poder levar evidências e provar suas alegações no julgamento, tendo em vista as exclusionary rules, ocorre ali a verdadeira disputa entre acusação e defesa, cabendo ao acusado aceitar ou não a negociação firmada por seu representante - o defensor. Caso não haja concordância, os procedimentos preliminares se desenvolvem, para culminar no trial by jury.

E é justamente aqui que os questionamentos do Federal Prosecutor no caso dos fuzis, tal como descrito acima, ganham alta relevância, pois explicitam o contraste entre os cuidados com a produção legítima da prova no Brasil e nos Estados Unidos. Lá, diferentemente do Brasil, não são só as provas ilícitas que são inadmitidas no processo penal. Em razão do processo pertencer às partes e não ao Estado, na plea bargain tanto a acusação quanto a defesa ficam atentas ao conjunto de vestígios existente, que sejam de fato passíveis de serem trazidos ao julgamento por cada uma delas, em função de sua adequação às regras de admissão de evidências (evidence). A aplicação e o zelo à essas regras se realiza em audiências preliminares, em que as partes, diante do juiz, discutem o que pode e o que não pode ser levado ao julgamento (BISHARAT, 2015). Um exemplo são as discussões sobre a possibilidade de mencionar, ou não, os antecedentes das testemunhas durante o processo. Cada caso é discutido em função de sua especificidade, como o tipo e a gravidade dos antecedentes criminais de cada uma das testemunhas à luz da jurisprudence disponível, para que o juiz tome sua decisão. Estas preliminares irão decidir os riscos envolvidos na realização do julgamento, referentes à provável condenação ou absolvição. Assim, a devida obediência das partes aos regramentos legais para produção da prova acarreta profunda repercussão no processo de negociação, em que a defesa busca apontar os possíveis vícios que possam influenciar na rejeição dessa ou daquela evidência, conseguindo assim uma melhor posição no processo de negociação. Do outro lado a acusação aponta justamente a regularidade e qualidade de cada evidência, objetivando fortalecer sua posição e justificar uma negociação com penas mais altas. Veja-se que tais indícios são acautelados cuidadosamente para serem levados ao Tribunal na ocasião do julgamento, procedimento que, no Brasil, pode ou não ocorrer, haja vista que os autos do processo, certificados pelo cartório, representam de forma fidedigna os vestígios e evidências disponíveis.

Segundo a literatura disponível sobre o assunto, lá, a cadeia de custódia é: 
o processo mais crítico de documentação de evidências. Deve assegurar ao tribunal que a prova é autêntica, por exemplo, que é a mesma prova apreendida na cena do crime. Esteve, ao longo do tempo, sob a custódia de uma pessoa designada para lidar com ela e que não deixou de ser acompanhada. Embora seja um processo longo, é necessário para que a prova tenha relevância no julgamento. A continuidade da posse sobre as provas e sua custódia, bem como seu movimento e localização desde a sua descoberta até a sua recuperação (na cena do crime ou por uma pessoa), até o seu transporte para o laboratório para exame, até o momento em que é aceita e admitida na corte, é conhecido como cadeia de custódia ou de evidências. ${ }^{26}$

Nesse sentido, o grau de detalhamento que segue esse processo, é importante porque é ele que garante a "integridade de parte da prova. Um registro sobre as pessoas que lidaram com o material é mantido, de modo que a pessoa que esteve cuidando dele possa ser chamada a testemunhar, a qualquer tempo. (...) Um registro da cadeia precisa ser mantido e comprovado no tribunal, sempre que uma evidência for apresentada como um "exhibit". Sem isso, pode ser inadmissível no tribunal, provocando sérias questões a respeito de sua legitimidade, integridade e os testemunhos a seu respeito. A cadeia de custódia deve documentar cada transferência pela qual a prova passa" ${ }^{27}$. A evidência requer tratamento consciencioso para prevenir sua manipulação fraudulenta. (...) é importante que esteja registrada toda e qualquer sequência de custódia, controle, transferência, análise e disposição de evidências físicas e eletrônicas. (...) O objetivo é demonstrar que a evidência é relacionada ao crime em julgamento, foi coletada na cena do crime e estava em suas condições originais inalteradas e não foi manipulada

\footnotetext{
${ }^{26}$ Tradução livre do trecho que segue: "The chain of custody is the most critical process of evidence documentation. It is a must to assure the court of law that the evidence is authentic, i.e., it is the same evidence seized at the crime scene. It was, at all times, in the custody of a person designated to handle it and for which it was never unaccounted. Although it is a lengthy process, it is required for evidence to be relevant in the court. The continuity of possession of evidence or custody of evidence and its movement and location from the point of discovery and recovery (at the scene of a crime or from a person), to its transport to the laboratory for examination and until the time it is allowed and admitted in the court, is known as the chain of custody or chain of evidence". Chain of Custody - StatPearls https://www.ncbi.nlm.nih.gov/books/NBK551677/ consultado em 28 fevereiro de 2021.

${ }_{27}$ Vide, para mais informações, os trechos originais: The chain of custody proves the integrity of a piece of evidence. A paper trail is maintained so that the persons who had charge of the evidence at any given time can be known quickly and summoned to testify during the trial if required. A record of the chain of evidence must be maintained and established in the court whenever presenting evidence as an exhibit. Otherwise, the evidence may be inadmissible in the court leading to serious questions regarding its legitimacy, integrity, and the examination rendered upon it. The chain of custody needs to document every transmission from the moment the evidence is collected, from one person to another, to establish that nobody else could have accessed or possessed that evidence without authorization. Although there is no limit on the number of transfers, it is crucial to keep this number as low as possible. Chain of Custody - StatPearls https://www.ncbi.nlm.nih.gov/books/NBK551677/. Acesso em: 28 fevereiro de 2021.
} 
fraudulentamente ou "plantada" para incriminar alguém² ${ }^{28}$. Assim, "a cadeia de custódia mantem a integridade da amostra. E a possibilidade de rastrear os registros de controle, transferência e análise indicam a transparência do procedimento. (...) Ela impede que os policiais e outros funcionários da perícia envolvidos corrompam a evidência ou a classifiquem erroneamente uma vez que isso poderia ser reconstituído até chegar neles e seriam responsabilizados (...) Durante o julgamento, se a defesa levanta dúvidas sobre a cadeia de evidência, os registros demostrarão que a identificação dela na acautelamento é a mesma da cena do crime. Entretanto, se inconsistências persistirem e a acusação não puder provar quem estava em poder da evidência num determinado momento, então a cadeia é considerada quebrada e a defesa pode pleitear no tribunal que a evidência seja anulada ${ }^{29} "$.

Por isso, ela não se refere somente ao tratamento da prova, mas se afigura em um procedimento que explicita como a prova foi tratada. Essa transparência contrasta com o que viemos demonstrando sobre a prova nos cartórios brasileiros, em que sequer os agentes do poder judiciário sabem dizer onde estão depositadas, porque o que tem valor probatório indiscutível são as declarações constantes sobre elas nos registros cartorários.

Vale o registro de que o plea bargain se funda e está conectada à beyond a reasonble doubt, ou seja, da probabilidade real de que existam provas contundentes e, é claro, legítimas para incriminar o acusado que, como já dissemos, não é considerado inocente das acusações, apenas not guilty em relação a elas, quando a acusação não consegue provar diante dos jurados, além de uma dúvida razoável, o que queria demonstrar. Essa dúvida razoável, por exemplo,

\footnotetext{
${ }^{28}$ Evidence requires conscientious handling to avert tampering. The chain of custody is said to be the sequential documentation or trail that accounts for the sequence of custody, control, transfer, analysis, and disposition of physical or electronic evidence. The goal is to establish that the evidence is related to the alleged crime, was collected from the scene, and was in its original/unaltered condition rather than having been tampered with or "planted" deceitfully to make someone seem guilty. Chain of Custody - StatPearls https://www.ncbi.nlm.nih.gov/books/NBK551677/. Acesso em: 28 fev., 2021.

${ }^{29}$ The chain of custody maintains the integrity of the sample. The traceability of the record of the control, transfer, and analysis of samples indicates the transparency to the procedure. Maintaining the chain of custody is critical in forensic practice. This step of documentation is vital because everything done for the examination and analysis of the evidentiary sample must be authorized and recorded. The liability for the condition rests with everyone coming in contact with it. The documentation should be comprehensive with information regarding the circumstances of evidence collection, the people who handled the evidence, period of the guardianship of evidence, safekeeping conditions while handling and/or storing of the evidence, and how evidence is handed over to subsequent custodians every time a transfer occurs (along with the signs of individuals involved at the respective stage). It prevents police officers and other labs/law officials involved from tainting the evidence or misplacing the piece of evidence as it would eventually be traceable back to them, and they would be held responsible for the same. (...) During the trial, if the defense counsel raises queries on the chain of evidence, the records will demonstrate that the iron rod in the evidence storage is the same as that collected from the scene of a crime. Still, if inconsistencies persist and the prosecution cannot prove who had the iron rod at a given point of time, then the chain is deemed broken, and the defense counsel may seek in the court to have the resultant evidence annulled. Chain of Custody - StatPearls https://www.ncbi.nlm.nih.gov/books/NBK551677/. Acesso em: 28 fev., 2021.
} 
pode ser a impossibilidade de a acusação demonstrar que a sua versão representa a única forma de conceber como os fatos se desenrolaram. Tendo a defesa demonstrado que o crime poderia ter ocorrido de outra maneira, a acusação não se sustenta em sua integridade e pode dar oportunidade ao surgimento de uma reasonable doubt.

Como ocorre na maioria dos processos dos $\mathrm{EUA}^{30}$, o caso aqui em questão não foi diferente, ou seja, foi resolvido através da negociação cooperativa, a plea bargaining, com a consequente aceitação de culpa - guilty - pelas partes. Essa aceitação, entretanto, foi parcial, em função das dificuldades em preservar as evidências do flagrante efetuado pela Polícia brasileira:

The United States of America and $\mathrm{FB}^{31}$ (the "Defendant") agree that, were this case to proceed to trial, the United States would prove beyond a reasonable doubt the following facts, among others, which occurred in the Southern District of Florida: ${ }^{32}$

Por contraste, no caso brasileiro, temos um processo penal que pertence ao Estado. Como dissemos, diante de indícios de materialidade e autoria, o promotor de justiça ou Procurador da República, tem a obrigação de oferecer a denúncia e, tendo em vista o princípio da indisponibilidade da ação penal, dela não pode desistir ${ }^{33}$. As provas, produzidas pela polícia de maneira inquisitorial e particularizada são entranhadas nos autos do processo e registradas e certificadas pelo cartório (KANT DE LIMA, 2019), passando a pertencer ao juiz e não às partes. O juiz, a seu turno, é quem controla a produção e a validade das provas no decorrer do processo, obrigatoriamente construído através de versões contraditórias dos indícios, fatos e provas, registrados nos seus autos, documento escrito e sob a guarda do cartório, e é a ele que cabe definir, em razão do "livre convencimento motivado", a ele assegurado por lei, em último caso, o que ficou provado e o que não ficou, independentemente das alegações das partes ${ }^{34}$ (GRINOVER, 1999; MENDES 2012; FIGUEIRA, 2008). Diante desse cenário, sendo os cartórios os certificadores de fé pública da autenticidade dos seus registros e o magistrado o

30 George E. Bisharat menciona que mais de $90 \%$ dos processos americanos são resolvidos através de negociação cooperativa, conhecida como plea bargaining (Bisharat, 2015, p. 158).

31 O nome do acusado foi propositalmente excluído.

32 Esse é o primeiro parágrafo do plea agreement celebrado no caso em análise.

33 Como define o art. 42 do CPP, " O Ministério Público não poderá desistir da ação penal”. Combinado com ele, está a Constituição brasileira que dá ao MP a titularidade da ação penal.

34 Art. 155 do Código de Processo Penal. 
dono do processo, como é possível pensar em regras capazes de limitar a sua avaliação das provas?

Nos perguntamos, assim, se a importação das regras de manutenção da prova, nesse sentido, serão adotadas pelos cartórios da justiça criminal ou, quem sabe, os cartórios extintos serão? Somente pesquisas empíricas sobre a implementação da "cadeia de custódia" no Brasil poderão nos demonstrar o que será feito com mais esse instituto, próprio de um sistema que representa os cidadãos de modo igualitário e onde vige um sistema penal acusatorial, aqui em nosso modelo piramidal e inquisitório (KANT DE LIMA, 2004).

\section{CONCLUSÃO}

Como temos demonstrado nos últimos anos, o funcionamento do sistema processual penal dos EUA baseia-se em regras procedimentais explícitas que se constituem em protocolos cuja execução correta legitima os resultados da ação dos agentes, protegendo-os e aos usuários de seus serviços de culpabilizações indevidas. (KANT DE LIMA, 2009, 2013). Existe, portanto, uma confiança sobre o que foi produzido na fase policial, justamente porque se presume tenham sido seguidos os protocolos devidos. Se por acaso esses protocolos não forem seguidos, os vestígios e indícios não podem ser levados a julgamento ou, se forem, podem ser desqualificados pela defesa e levar a um veredito de não culpabilidade, isto é, de que não foi possível provar a culpa do acusado com apoio nas evidências disponíveis. Ou seja, as regras de validade das provas passam por quesitos procedimentais, que asseguram que elas tenham sido mantidas de acordo com o que determinam os protocolos. Ainda, por ser um processo penal de forte orientação empírica, em que a busca dos agentes é pelo que se pode provar - verdade jurídica e não por uma verdade real, todos esses elementos são considerados, justificando-se a ritualização da apreensão de bens e pessoas, de modo rigoroso e explicitamente protocolar, para que possa ser reconstituído verbal e fisicamente no tribunal, no momento de realização do julgamento, influenciando os rumos da negociação relativa ao plea bargain.

Em nosso sistema, a garantia da integridade dos indícios reside nos registros cartorários, formal ou informalmente sigilosos para os acusados e seus representantes legais, juridicamente dotados de fé pública e validados seja pela autoridade policial, seja pelo magistrado, nos vários 
momentos de seus trâmites. Os protocolos, portanto, quando existem, são referentes à necessária confecção dos registros cartorários, que passam a substituir as evidências empíricas, inclusive as próprias declarações orais presenciais das testemunhas. O sistema, portanto, confia mais nesse postulado dogmático e doutrinário da fé pública dos registros cartorários, do que nas evidências empíricas de sua violação, que teriam que ser provadas pelas partes que as alegam. Enquanto que nos Estados Unidos, basta que se demonstre que os devidos protocolos, explícitos e transparentes para as partes, não foram seguidos para que se proponha a exclusão dessa evidência do processo.

Nosso texto representa um esforço de discutir a relevância da contribuição da perspectiva antropológica para a compreensão adequada, e consequente possível aperfeiçoamento do funcionamento de nosso "sistema de justiça criminal". Juntamente com outros autores (GARAPON E PAPADOPOULOS, 2008) efetuamos uma comparação por contraste entre sistemas da common law e da civil law, demonstrando que eles têm princípios e finalidades muito distintas, o que faz com que a circulação de institutos entre eles deve ser cercada de muitos cuidados para que surta os efeitos desejados. Sem esses cuidados há fortes possibilidades não só de os institutos não produzirem os efeitos desejados, mas também de produzirem efeitos não desejados, como foi recentemente o caso da importação da delação premiada pelo nosso sistema de justiça de orientação inquisitorial, que acabou por transformála e emprestar-lhe significado e efeitos muito próximos às confissões "diminuta" e "plena" do Regimento da Inquisição (KANT DE LIMA; MOUZINHO, 2016). No caso da "cadeia de custódia”, como é difícil prever a extinção dos cartórios em nosso sistema inquisitorial, a probabilidade maior é que as cadeias de custódia previstas neles se cartorializem na prática, transformando todos esses procedimentos empíricos e protocolares em declarações "a termo", fazendo com que os magistrados continuem buscando nas delegacias de polícia, após o termino dos processos, as informações acerca da localização dos bens descritos nos autos de apreensões formalizados nos inquéritos policiais com objetivo de cumprir o manual ${ }^{35}$ do Conselho Nacional de Justiça que orienta a atuação dos magistrados na destinação de bens apreendidos. Esse é o perigo da importação de institutos jurídicos sem considerar o contexto cultural em que ele está inserido, sob pena do efeito provocado ser completamente distinto daquele pretendido.

\footnotetext{
${ }^{35} \mathrm{O}$ CNJ editou uma cartilha intitulada "Manual de Bens Apreendidos" com objetivo de auxiliar os magistrados no destino de bens apreendidos, que se encontra disponível em: https://www.cnj.jus.br/wpcontent/uploads/2011/01/MANUAL_DE_GESTO_DOS_BENS_APREENDIDOS_cd.pdf. Acesso em 24 de março de 2021.
} 
Assim, para obter efeitos confiáveis e duradouros nas mudanças propostas para aperfeiçoar nosso sistema, buscando melhores controles e regulações, nada melhor do que explicitar as características inquisitoriais que tradicionalmente o orientam, ao invés de negá-las doutrinariamente no mundo do “dever ser", que não tem sua validade fundamentada nas práticas dos agentes do sistema, como ocorre, por exemplo, com o sistema francês (GERALDO, 2019; KANT DE LIMA; GERALDO, 2021).

Enquanto insistirmos em afirmar o caráter pseudo-acusatório de nosso sistema, que na prática permanece vinculado às tradições inquisitoriais de suas raízes eclesiásticas católicas e estatais (KANT DE LIMA; MOUZINHO, 2016), não conseguiremos controlar a arbitrariedade dos seus agentes e continuaremos a conviver com um contexto processual penal que não se coaduna com os ideais republicanos expressos em nossa Constituição.

\section{REFERÊNCIAS BIBLIOGRÁFICAS:}

AMORIM, Maria Stella; KANT DE LIMA, Roberto; MENDES, Regina L. T. (Orgs.). Introdução. In: Ensaios sobre a Igualdade Jurídica: acesso à justiça criminal e direitos de cidadania no Brasil. Rio de Janeiro: Lúmen Júris, 2005. p. XI-XXXVIII.

ABREU, João Vitor Freitas Duarte. A custodia das audiências: Uma análise das práticas decisórias na Central de audiências de custódia (CEAC) do Rio de Janeiro. Dissertação (Mestrado em Sociologia e Direito). Universidade Federal Fluminense. 2019.

BISHARAT, George. The plea bargain machine. Revista Dilemas, v. 7, n. 3, jul/ago/set 2014., p. 767-795. Disponível em: <http://revistadil.dominiotemporario.com/doc/DILEMAS-7-3Art6.pdf >. Acesso em: 02 abr. 2015. Tradução brasileira em The plea bargain machine. In Duarte, F., Iorio Filho, R. M. e Kant de Lima, R., (orgs) O Judiciário nos Estados Unidos e no Brasil: análises críticas e pesquisas comparadas. Curitiba, Ed. CRV, 2015, p. 157-186.

BRASIL. MANUAL DE BENS APREENDIDOS. Brasília, CNJ. www.cnj.jus.br. Disponível em: https://www.cnj.jus.br/wpcontent/uploads/2011/01/MANUAL_DE_GESTÃO_DOS_BENS_APREENDIDOS_cd.pdf. Acesso em 24 de março de 2021.

CASTRO, Carlos Roberto Siqueira. O Devido Processo Legal e os Princípios da Razoabilidade e da Proporcionalidade. Rio de Janeiro: Forense. 2010. p. 273.

DUMONT, Louis. O individualismo: uma perspectiva antropológica da ideologia moderna. Rio de Janeiro, Rocco: 1985. 
FERREIRA, Marco Aurélio Gonçalves. O Devido Processo Legal: um estudo comparado. Rio de Janeiro: Lumen Juris, 2004.

FERREIRA, Marco Aurélio Gonçalves. A presunção da inocência e a construção da verdade. Rio de Janeiro, Lumen Juris, 2013.

FIGUEIRA, Luiz Eduardo. O Ritual Judiciário do Tribunal do Júri. Porto Alegre, Sergio Antonio Fabris Editor, 2008

FIGUEIRA, Luiz Eduardo. A Produção da Verdade nas Práticas Judiciárias Criminais Brasileiras: uma perspectiva antropológica de um processo criminal. Niterói, EDUFF, 2005.

FOUCAULT, Michel. A Verdade e as Formas Jurídicas. Rio de Janeiro, PUC/RJ, 1999.

FRANCO, Ary de A. O Júri e a Constituição Federal de 1946. Rio de Janeiro, Revista Forense, 1956.

GARAPON, A e PAPADOPOULOS, I . Julgar nos Estados Unidos e na França. Rio de Janeiro, Lumen Juris, 2008.

GEERTZ, Clifford. Local Knowledge: fact and law in comparative perspective. In Clifford Geertz, Local Knowledge. further essays in intepretive anthropology, 1983, p. 167-234.

GERALDO, Pedro Heitor Barros. Políticas Públicas Judiciárias: uma abordagem comparativa entre a organização social da Justiça no Brasil e na França. In Revista Juris Poiesis, v. 22, p. 309-328, 2019.

GLUCKMAN, Max. O material etnográfico na antropologia social inglesa. In: ZALUAR, Alba (ed). Desvendando máscaras sociais. Rio de Janeiro: Francisco Alves, p. 63-76, 1975.

GRINOVER, A. P, A iniciativa instrutória do juiz no processo penal acusatório. Revista Brasileira de Ciências Criminais, v. 27, p. 71-79, 1999

KANT DE LIMA, Roberto. A Polícia da Cidade do Rio de Janeiro. Seus dilemas e paradoxos. $3^{\text {a }}$ ed. rev. Amazon, 2019.

KANT DE LIMA, Roberto. Direitos civis e direitos humanos: uma tradição judiciária prérepublicana?. São Paulo em Perspectiva, v. 18, n. 1, p. 49-59, 2004.

KANT DE LIMA, Roberto. Ensaios de Antropologia e de Direito: acesso à justiça e processos institucionais de administração de conflitos e produção de verdade em uma perspectiva comparada. Rio de Janeiro: Lumen Juris, 2009.

KANT DE LIMA, Roberto . Entre as leis e as normas: éticas corporativas e práticas profissionais na segurança pública e na Justiça Criminal. Dilemas: Revista de Estudos de Conflito e Controle Social, v. 6, p. 549-580, 2013.

KANT DE LIMA, Roberto; Mouzinho, G. Produção e reprodução da tradição inquisitorial no Brasil: entre delações e confissões premiadas. In Dilemas. Rio de Janeiro, vol9, no.3, set/dez 2016. p.505-529 
KANT DE LIMA, Roberto; GERALDO, P. H. B. - A Ética dos Operadores de Direito e o espírito da Lava-Jato. In JOTA INFO, 05 de março de 2021. Disponível em https://mail.google.com/mail/u/0/\#label/artigos/WhctKJWQhmcWbLVDWlnvGmwpczfmspr nlvcfLVNxqJPHzsXSxFGzsGVvQVswcFhqklrxkBg. Acessado em 13 de março de 2021.

KANT DE LIMA, Roberto; MOUZINHO, Gláucia; NUÑEZ, Izabel Saenger. Vaza Jato: descoberta de ilegalidades privilegiadas ou explicitação de meras rotinas?. Insighth Inteligência, Rio de Janeiro, p. 72 - 81.

LOBO, Michel. Nem Todo Morto é Vítima: Práticas e Negociações Jurídico-Policiais na Administração e Investigação de Homicídios Dolosos, Tese de doutorado em Sociologia/IESP/UERJ Ano de obtenção: 2018.

MENDES, Regina Lucia Teixeira. 2012. Do princípio ao livre convencimento motivado: legislação, doutrina e interpretação de juízes brasileiros. Rio de Janeiro: Lumen Juris.

MISSE, Michel. O Inquérito Policial no Brasil. Uma pesquisa empírica. Rio de Janeiro, Editora Booklink, FENAPE, NECVU, 2010.

NUÑEZ, Izabel Saenger. Dogmas e doutrinas: verdades consagradas e interpretações sobre o tribunal do júri. 1. ed. Rio de Janeiro: Autografia, 2018.

NUÑEZ, Izabel Saenger. Aqui nós somos uma família: brigas e acordos no Tribunal do Júri. Rio de Janeiro: Autografia, 2021.

PAIXÃO, Antônio Luiz. A organização policial numa área metropolitana. Dados, v. 25, n. 1, p. 63-85, 1982.

PIMENTA BUENO, José Antonio. Apontamentos sobre o Processo Criminal pelo Jury. Typ. Imperial e Constitucional: Rio de Janeiro, 1849. 